\title{
Evaluation of Obese Adolescents Using the Rosenberg Self-esteem Scale
}

\author{
(D) Hüseyin Dağ1,2, (D) Emine Türkkan² \\ 1 Istanbul University Institute of Child Health, Department of Pediatric Basic Sciences, Division of Adolesance Health, Istanbul, Turkey \\ 2University of Health Sciences Turkey, Prof. Dr. Cemil Taşcıoğlu City Hospital, Clinic of Pediatrics, Istanbul, Turkey
}

\section{Abstract}

Objective: Obesity, is a global public health problem characterized by excessive body fat deposition in the body, it causes physical as well as mental problems but also such as anxiety, depression, and low self esteem. The aim of this study was to investigate the psychological problems associated to adolescent obesity.

Methods: Thirty-three obese voluntee patients of the pediatric outpatient clinic, and thirty non-obese routine volunteers were included in the study. Adolescents with a body mass index (BMI) of $95 \%$ and above with respect their gender and age were considered obese. In adolescents of the control group, BMI varied between the $5^{\text {th }}$ and $<85^{\text {th }}$ percentile for their age and gender. All participants were evaluated using the Rosenberg self-esteem scale during direct interviews, with outcomes being of self-esteem, anxiety, depression, and isolation.

Results: The study included 63 adolescents, 33 (52.4\%) females and 30 (47.6\%) males, aged between 10 and 16 years. Self-esteem and anxiety were varied significantly between the groups $(p<0.05)$. However, there was no statistically significant difference between the groups regardingdepression and social isolation $(p>0.05)$.

Conclusion: Although adolescent obesity prevention strategies are important, appropriate counseling should also be provided concerning mental health issues like anxiety and low self-esteem.

Keywords: Adolescent, obesity, psychopathology

\section{INTRODUCTION}

Obesity is a metabolic disorder associated to physical and mental problems resulting from excessive body fat deposition. Obesity is a complex disorder resulting from an imbalance between calorie intake and consumption $(1,2)$. Obesity, which can begin in childhood, is an important public health problem with social and economic scopes that significantly influence morbidity and mortality. The World Health Organization defined childhood obesity as one of the most important problems of the $21^{\text {st }}$ century. It has been reported that 340 million children and adolescents aged between 5 and 19 years are affected by overweight and obesity (3).
One of the comorbid diseases accompanying obesity is psychosocial problems, anxiety, and depression. Some studies have delineated that childhood depression, anxiety, and obesity show a parallel course $(4,5)$. The study aim was to evaluate obese adolescents using the Rosenberg self-esteem scale and to provide these patients with the necessary support through a multidisciplinary approach.

\section{METHODS}

This study was conducted after ethical approval from the Clinical Research Ethics Committee of Okmeydani Training and Research Hospital's decision dated 08/01/2019 and numbered 1092 was 
issued. Inform consent was obtained from both participating adolescents and their families. Thirty-three obese volunteers of the pediatric outpatient clinic (study group); and thirty nonobese healthy routine volunteers with normal percentiles and without any chronic diseases (control group) according to the monitoring program of the Ministry of Health were included in the study. Obesity was determined according to body mass index (BMI) as a criterion. BMI was calculated as equal to the body weight (in kilograms) divided by the height in squared meters $\left(\mathrm{kg} / \mathrm{m}^{2}\right)$. Adolescents with a BMI of $95 \%$ and above with respect to their gender and age were defined as obese (6). In the control group, BMI was between the $5^{\text {th }}$ and $<85^{\text {th }}$ percentile according to their gender and age.

Four outcomes of the Rosenberg Self-Esteem scale, translated into Turkish by Çuhadaroglu and consisted of 12 outcomes, were administered to all participants $(7,8)$. These sub-headings, including self-esteem, depressive affect, psychosomatic symptoms, and psychosocial isolation, were applied through direct interviews using a questionnaire. Participants with any underlying chronic diseases and under treatment, presenting any genetic disorder, who refused to participate in the study, and who could not read and write Turkish were excluded from the study.

\section{Statistical Analysis}

IBM SPSS Statistics 22 (IBM SPSS, Turkey) software was used for statistical analysis. During data analysis, the conformity of the parameters to the normal distribution was evaluated using the Shapiro-Wilks test; and the parameters did not follow normal distribution. Thus, the Mann-Whitney $U$ test was used for the comparison of quantitative data and parameters between two groups as well as descriptive analysis (mean, standard deviation, frequency). Chi-square test, Fisher Freeman Halton test, and continuity (yates) correction were used for qualitative data analysis. The Significance level was set at the $p<0.05$ level.

\section{RESULTS}

The study included 63 children, 33 (52.4\%) girls and 30 (47.6\%) boys, aged between 10 and 16 years. The mean and median ages were $13.79 \pm 1.17$ years, and 14 years respectively. Children were evaluated under two groups as "Obese" $(\mathrm{n}=33)$ and "Control" $(n=30)$. There was no statistically significant difference between the groups in terms of mean age and gender distribution $(p>0.05)$.

The score comparison of both groups is illustrated in Table 1. Self-esteem and anxiety scores were significantly different between groups $(p<0.05)$. There was no statistical disparity in terms of social isolation and depression. Even though there was no significant difference with respect to depression, the depression level was higher in the obese group.

Both groups were compared for these scores with reference to gender in Table 2. There was no significant difference between the scores in both the obese and control groups as regards to gender.

As illustrated in Table 3, there was a significant difference in terms of self-esteem and anxiety levels when the groups were classified according to the scores.

\section{DISCUSSION}

Despite the fact that there was no significant difference regarding the depression scores between the obese and control groups in our study, depression levels were found to be higher in the obese group. It has been revealed in some studies that obese children display more depression and anxiety related symptoms than their normal-weight peers $(9,10)$. In a study by Lindberg et al. (11), the rate of depression was reported to be statistically significantly higher in obese children and adolescents. Consistent with these findings, Gibson et al. (12) conveyed that there was an association between increased (age- and gender-specific) BMI and higher depression levels in primary school-aged children. Mustillo et al. (13) found a relationship between obesity and depression in boys aged between 9 and 16 years. Anderson et al. (14) revealed a significant relationship between obesity and major depression in adolescent girls. In another meta-analysis, it was reported that obesity increases the risk of depression and that depression in return increases the probability of developing obesity. As a result, it would be beneficial to monitor overweight and obese patients for depression risk and as well evaluate patients with depression for obesity (15). In this study mentioned, despite the fact that there was no significant difference in terms of depression level, the depression score was found to be higher in the obese group. Due to the cross-sectional nature of our study,

Table 1. Group evaluation in terms of self-esteem, depression, anxiety, and isolation scores

\begin{tabular}{|l|l|l|l|}
\hline & Obese $(\mathbf{n}=33)$ & Control $(\mathbf{n}=30)$ & \multirow{2}{*}{$p$} \\
\cline { 2 - 3 } & $\begin{array}{l}\text { Mean } \pm \text { SD } \\
\text { (median) }\end{array}$ & $\begin{array}{l}\text { Mean } \pm \text { SD } \\
\text { (median) }\end{array}$ & \\
\hline Self-esteem score & $1.83 \pm 1.39(1.83)$ & $0.86 \pm 0.94(0.5)$ & $0.000^{*}$ \\
\hline Depression score & $2.36 \pm 1.71(2)$ & $1.5 \pm 1.33(1)$ & $0.024^{*}$ \\
\hline Anxiety score & $5.18 \pm 2.01(5)$ & $3.57 \pm 2.37(3)$ & $0.002^{*}$ \\
\hline Isolation score & $1.21 \pm 0.82(1)$ & $0.77 \pm 0.86(0.5)$ & $0.040^{*}$ \\
\hline${ }^{*} p<0.05$, Mann-Whitney U test, SD: Standard deviation \\
\hline
\end{tabular}




\begin{tabular}{|c|c|c|c|c|c|}
\hline \multirow{2}{*}{ Groups } & \multirow{2}{*}{ Gender } & Self-esteem score & Depression score & Anxiety score & Isolation score \\
\hline & & Mean \pm SD (median) & Mean \pm SD (median) & Mean \pm SD (median) & Mean \pm SD (median) \\
\hline \multirow[t]{2}{*}{ Obese } & Male & $1.6 \pm 1.59(0.7)$ & $2.13 \pm 1.82(1.5)$ & $5.5 \pm 1.9(5.5)$ & $1.13 \pm 0.72(1)$ \\
\hline & $p$ & 0.102 & 0.246 & 0.352 & 0.427 \\
\hline \multirow[t]{2}{*}{ Control } & Male & $0.67 \pm 0.47(0.5)$ & $1.5 \pm 1.09(1)$ & $3 \pm 2.42(2.5)$ & $0.64 \pm 0.84(0)$ \\
\hline & $p$ & 0.350 & 0.663 & 0.101 & 0.455 \\
\hline
\end{tabular}

\begin{tabular}{|c|c|c|c|c|}
\hline & & \multirow{2}{*}{\begin{tabular}{|l} 
Obese \\
$\mathrm{n}(\%)$ \\
\end{tabular}} & \multirow{2}{*}{\begin{tabular}{|l|} 
Control \\
$\mathrm{n}(\%)$ \\
\end{tabular}} & \multirow{2}{*}{$p$} \\
\hline & & & & \\
\hline \multirow{3}{*}{ Self-esteem } & High & $15(45.5 \%)$ & $24(80 \%)$ & \multirow{3}{*}{${ }^{1} 0.012^{*}$} \\
\hline & Medium & $16(48.5 \%)$ & $5(16.7 \%)$ & \\
\hline & Low & $2(6.1 \%)$ & $1(3.3 \%)$ & \\
\hline \multirow{4}{*}{ Depression } & No depression & $2(6.1 \%)$ & $6(20 \%)$ & \multirow{4}{*}{${ }^{1} 0.087$} \\
\hline & Mild & $15(45.5 \%)$ & $18(60 \%)$ & \\
\hline & Moderate & $10(30.3 \%)$ & $4(13.3 \%)$ & \\
\hline & Severe & $6(18.2 \%)$ & $2(6.7 \%)$ & \\
\hline \multirow{3}{*}{ Anxiety } & Mild & $1(3 \%)$ & $10(33.3 \%)$ & \multirow{3}{*}{${ }^{2} 0.001 *$} \\
\hline & Moderate & $10(30.3 \%)$ & $12(40 \%)$ & \\
\hline & Severe & $22(66.7 \%)$ & $8(26.7 \%)$ & \\
\hline \multirow{2}{*}{ Isolation } & Mild & $16(48.5 \%)$ & $21(70 \%)$ & \multirow{2}{*}{${ }^{3} 0.140$} \\
\hline & Severe & $17(51.5 \%)$ & $9(30 \%)$ & \\
\hline
\end{tabular}

${ }^{1}$ Fisher Freeman Halton test, ${ }^{2}$ Chi-square test, ${ }^{3}$ Continuity (yates) correction, ${ }^{*} \mathrm{p}<0.05$

other accompanying psychological disorders would be detected with longer follow-up periods and new interviews repeated.

In this study, the anxiety level was found to be significantly higher in obese adolescents. Consistent with the literature, it was revealed that obese children often frequently experience internal mental distress such as anxiety (16-19). If these patients do not receive support, they will probably continue to experience various forms of internal mental illnesses in the next stage. Contrary to our study, some studies suggest that the relationship between anxiety and obesity is unclear (20).

A meta-analysis of obese adolescents delineated that the overall prevalence of depression and anxiety symptoms among overweight/obese children and adolescents was $21.73 \%$ and $39.80 \%$, respectively, and $17.96 \%$ and $13.99 \%$, respectively, among non-overweight/non-obese children and adolescents (21). In a study by Topçu et al. (22) higher anxiety levels, depression, and low self-esteem were diagnosed in obese adolescents. Notwithstanding that we found higher anxiety levels in our study in the obese group, similar to the literature, we did not find a significant difference between the groups in terms of depression rates. The fact that the scales we used were different and the numbers in the patient groups were not similar may have created the difference in terms of results.

Adolescents are very concerned about their physical appearance with the effect of hormones during the transition to adulthood. Since emotional relationships can also be experienced during this period, the desire to be liked/approved becomes prominent (23-25). Therefore, those who are overweight or obese have more self-esteem problems. Another important finding in our study was that the self-esteem of the obese group was significantly lower than in the control group. Similarly, in the study by ÁlvarezGarcía et al. (26) in a large adolescent group and the study by Çolpan et al. (27) on adolescents, it was reported that obese and overweight individuals had lower self-esteem and more conflict with their peers.

In our study, there was no difference between the two groups in terms of social isolation. However, we believe that obese adolescents will be more socially isolated in the following periods due to the higher anxiety and lower self-esteem levels. In some studies, it has been observed that low self-esteem is associated with social isolation $(28,29)$.

\section{Study Limitations}

The sample size of this study is relatively small. Moreover, since our study is a cross-sectional study, it does not reveal how the psychological effects of obesity will change over time. Whether patients with high anxiety rates will experience more depression over time or whether these patients will experience more social isolation can only be understood with follow-up. The design of future studies on this subject should be arranged with longer follow-up periods. 


\section{CONCLUSION}

In conclusion, obesity and its effects continue to manifest themselves as a public health concern. In practice, healthcare professionals must recognize that obese adolescents constitute a specific group. While struggling with obesity in adolescents, they should also be provided with the necessary psychological support.

\section{Ethics}

Ethics Committee Approval: This study was conducted after ethical approval from the Clinical Research Ethics Committee of Okmeydani Training and Research Hospital's decision dated 08/01/2019 and numbered 1092 was issued.

Informed Consent: Inform consent was obtained from both participating adolescents and their families.

Peer-review: Externally peer-reviewed.

\section{Authorship Contributions}

Concept: H.D., Design: H.D., E.T., Data Collection or Processing: H.D., E.T., Analysis or Interpretation: E.T., Literature Search: H.D., Writing: H.D., E.T.

Conflict of Interest: No conflict of interest was declared by the authors.

Financial Disclosure: The authors declared that this study received no financial support.

\section{REFERENCES}

1. Skinner AC, Ravanbakht SN, Skelton JA, Perrin EM, Armstrong SC. Prevalence of obesity and severe obesity in US children, 1999-2016. Pediatrics 2018;141.

2. Headid lii RJ, Park SY. The impacts of exercise on pediatric obesity. Clin Exp Pediatr 2021;64:196-207.

3. Romanelli R, Cecchi N, Carbone MG, Dinardo M, Gaudino G, Miraglia Del Giudice E, et al. Pediatric obesity: prevention is better than care. Ital J Pediatr 2020;46:103.

4. Williams YV, Cowan PA, Graff JC. Depressive symptoms, body mass index, and physical activity self-efficacy in African American Children. J Child Fam Stud 2020;27:1-10.

5. Valerio G, Maffeis C, Saggese G, Ambruzzi MA, Balsamo A, Bellone S, et al. Diagnosis, treatment and prevention of pediatric obesity: consensus position statement of the Italian Society for Pediatric Endocrinology and Diabetology and the Italian Society of Pediatrics. Ital J Pediatr 2018;44:88.

6. Smith SM, Gately P, Rudolf M. Can we recognise obesity clinically? Arch Dis Child 2008;93:1065-6.

7. Rosenberg, M. Society and Adolescent Self-Image. Princeton, NJ: Princeton University Press, 1965.

8. Çuhadaroğlu F. Self-esteem in the adolescents. Ankara: Hacettepe University; 1986
9. Quek YH, Tam WWS, Zhang MWB, Ho RCM. Exploring the association between childhood and adolescent obesity and depression: a metaanalysis. Obes Rev 2017;18:742-54.

10. Esposito M, Gallai B, Roccella M, Marotta R, Lavano F, Lavano SM, et al. Anxiety and depression levels in prepubertal obese children: a casecontrol study. Neuropsychiatr Dis Treat 2014;10:1897-902.

11. Lindberg L, Hagman E, Danielsson P, Marcus C, Persson M. Anxiety and depression in children and adolescents with obesity: a nationwide study in Sweden. BMC Med 2020;18:30.

12. Gibson LY, Allen KL, Davis E, Blair E, Zubrick SR, Byrne SM. The psychosocial burden of childhood overweight and obesity: evidence for persisting difficulties in boys and girls. Eur J Pediatr 2017;176:925-33.

13. Mustillo S, Worthman C, Erkanli A, Keeler G, Angold A, Costello EJ. Obesity and psychiatric disorder: developmental trajectories. Pediatrics 2003;111:851-9.

14. Anderson SE, Cohen P, Naumova EN, Jacques PF, Must A. Adolescent obesity and risk for subsequent major depressive disorder and anxiety disorder: prospective evidence. Psychosom Med 2007;69:740-7.

15. Türkiye Endokrinoloji ve Metabolizma Derneği. Obezite tanı ve tedavi kılavuzu. 8. Baskı, Ankara: Türkiye Endokrinoloji ve Metabolizma Derneği. 2019.

16. Eschenbeck H, Kohlmann CW, Dudey S, SchurholzT. Physician-diagnosed obesity in German 6- to 14-year-olds. Prevalence and comorbidity of internalising disorders, externalising disorders, and sleep disorders. Obes Facts 2009;2:67-73.

17. Williams J, Wake M, Hesketh K, Maher E, Waters E. Health-related quality of life of overweight and obese children. JAMA 2005;293:70-6.

18. Hwang JW, Lyoo IK, Kim BN, Shin MS, Kim SJ, Cho SC. The relationship between temperament and character and psychopathology in community children with overweight. J Dev Behav Pediatr 2006;27:1824.

19. Melnyk BM, Small L, Morrison-Beedy D, Strasser A, Spath L, Kreipe R, et al. Mental health correlates of healthy lifestyle attitudes, beliefs, choices, and behaviors in overweight adolescents. J Pediatr Health Care 2006;20:401-6.

20. Lamertz CM, Jacobi C, Yassouridis A, Arnold K, Henkel AW. Are obese adolescents and young adults at higher risk for mental disorders? A community survey. Obes Res 2002;10:1152-60.

21. Wang S, Sun Q, Zhai L, Bai Y, Wei W, Jia L. The prevalence of depression and anxiety symptoms among overweight/obese and non-overweight/ non-obese children/adolescents in China: a systematic review and meta-analysis. Int J Environ Res Public Health 2019;16:340. Published 2019 Jan 26. doi:10.3390/ijerph16030340

22. Topçu S, Orhon FŞ, Tayfun M, Uçaktürk SA, Demirel F. Anxiety, depression and self-esteem levels in obese children: a case-control study. J Pediatr Endocrinol Metab 2016;29:357-61.

23. Juvonen J, Lessard LM, Schacter HL, Suchilt L. Emotional implications of weight stigma across middle school: the role of weight-based peer discrimination. J Clin Child Adolesc Psychol 2017;46:150-8.

24. Vannatta K, Gartstein MA, Zeller M, Noll RB. Peer acceptance and social behavior during childhood and adolescence: how important are appearance, athleticism, and academic competence? Int J Behav Dev 2009;3:303-11.

25. Gil Madrona P, Romero Martínez SJ, Sáez-Gallego NM, Ordóñez Camacho $X G$. Psychomotor limitations of overweight and obese five-year-old children: influence of body mass indices on motor, perceptual, and social-emotional skills. Int J Environ Res Public Health 2019;16:427. 
26. Álvarez-García D, Núñez A, Pérez-Fuentes MDC, Núñez JC. Peer victimization in overweight adolescents and its effect on their selfesteem and peer difficulties. Int J Environ Res Public Health 2019;17:16.

27. Colpan M, Eray \$, Eren E, Vural AP. Perceived expressed emotion, emotional and behavioral problems and self-esteem in obese adolescents: a case-control study. J Clin Res Pediatr Endocrinol 2018;10:357-63.
28. Abdollahi A, Abu Talib M, Mobarakeh MRV, Momtaz V, Mobarake RK. Body-esteem mediates the relationship between self-esteem and social anxiety: the moderating roles of weight and gender. Child Care Pract 2016;2:296-308.

29. Seema GB, Kumar GV. Self-esteem and social anxiety in adolescent students. Indian J Posit Psychol 2017;8:435-8. 